\title{
O MARTÍRIO DO PADRE E DOS CAVALEROS: PERSPECTIVAS DO "MORRER PELA FÉ" EM GIL VICENTE E EM JOSÉ DE ANCHIETA
}

\section{THE PRIEST AND THE KNIGHT'S MARTYRDOM: PERSPECTIVES ON “DYING FOR ONE'S FAITH” IN GIL VICENTE AND IN JOSÉ DE ANCHIETA}

http://dx.doi.org/10.11606/issn.2175-3180.v12i23p117-132

Marina Gialluca Domene ${ }^{\mathrm{I}}$

\section{RESUMO}

O tema da morte - e o que acontece depois dela é recorrente na arte medieval europeia. O teatro português do período, tendo encontrado seu apogeu em Gil Vicente, encontra também no mestre uma discussão sobre diferentes tipos de almas, de mortes e de destinos. Poucas décadas depois, do outro lado do Oceano Atlântico, a colônia portuguesa na América viu o padre jesuíta José de Anchieta encenar, com a ajuda de outros padres e também de nativos, peças que também discutiam o tema. Este artigo lança o olhar sobre as consequências eternas do martírio religioso. Morrer pela fé católica parece garantir não só a entrada no Paraíso, como também um certo prestígio diante de representantes divinos. Pretendemos analisar de duas peças: o Auto da Barca do Inferno, de Gil Vicente, em que quatro Cavaleiros de Cristo são recebidos com honrarias pelo Anjo barqueiro, e o Diálogo de Pero Dias mártir, de José de Anchieta, em que um jesuíta martirizado em alto-mar conversa com o próprio Cristo. O que propomos é perceber as relações dialógicas entre os textos: a inserção em uma mesma tradição teatral e o estabelecimento de uma mesma moral cristã católica quinhentista.

\section{PALAVRAS-CHAVE}

Gil Vicente; José de Anchieta; Teatro religioso; Morte; Salvação.

\section{ABSTRACT}

The theme of death - and what happens after it - is recurring in European medieval art. Portuguese drama at this time, having found its heyday in Gil Vicente, also finds in the master a discussion on different kinds of souls, deaths and fates. Few decades later, on the other side of the Atlantic Ocean, the Portuguese colony in America saw the Jesuit priest José de Anchieta perform, with the help of other priests and also natives, plays which discussed the theme too. This paper casts its eyes over the eternal consequences of religious martyrdom. To die for the catholic faith seems to guarantee not only admittance to Heaven, but also some sort of prestige before divine representatives. We intend to analyze two plays: Auto da Barca do Inferno, by Gil Vicente, in which four Templar Knights are received with honors by the Angel in the boat, and Diálogo de Pero Dias mártir, by José de Anchieta, in which a Jesuit martyred on the high seas talks to Christ Himself. What we propose is to perceive dialogical relations between the two texts: their insertion in the same theatrical tradition and the establishment of the same 16th century Catholic Christian moral.

\section{KEYWORDS}

Gil Vicente; José de Anchieta; Religious drama; Death; Salvation.

I Universidade de São Paulo, São Paulo, Brasil. 


\section{UMA APRESENTAÇ̃̃O}

Neste artigo, partindo de um objeto de estudo que será o interesse principal de um futuro doutorado, propomo-nos a discutir duas peças de diferentes autores em que um mesmo tema é abordado de maneiras distintas. Ambas as peças, o Diálogo de Pero Dias, de José de Anchieta, e o Auto da Barca do Inferno, de Gil Vicente, apresentam aos olhos do espectador e do leitor almas humanas, que, após terem morrido pela fé, são recebidas por representantes divinos e encaminhadas para o Paraíso. Pretendemos analisar essas aparições em uma e outra peça, discutindo de que maneira essas almas são recebidas, a fim de realçar as características únicas de cada texto, considerando o que diz Dalila Pereira Costa em seu livro Gil Vicente e sua época. Essa lógica também será aplicada ao teatro de Anchieta.

Se a ideia da morte é mais reveladora da essência do pensamento do homem do que a ideia da vida, cumpre, em relação a Gil Vicente e à sociedade portuguesa sua contemporânea, curvarmo-nos sobre suas manifestações; e que no poeta estarão esparsas ao longo de toda sua obra e muito em particular concentradas na chamada Trilogia [...]. (COSTA, 1989, p. 57)

Como testemunhos das obras, nossa análise será baseada nas edições presentes em Gil Vicente: Autos, organizado por Cleonice Berardinelli, e em Poemas - Manuscritos do século XVI, em português, castelhano, latim e tupi, transcrito por Maria de Lourdes de Paula Martins.

O Auto da Barca do Inferno é um texto bastante difundido e muito conhecido. Não faremos um resumo detalhado da trama, entretanto, elencaremos alguns elementos do enredo que serão vitais para a análise. $\mathrm{O}$ outro texto escolhido e seu autor parecem habitar certa região obscura na historiografia da literatura brasileira e mundial. Portanto, com a licença do leitor, começaremos as duas partes principais deste texto com um rápido resumo dos pontos que nos interessam.

Apesar das léguas e das décadas que separam os textos, ambos pertencem a uma mesma tradição literária e a um mesmo contexto religioso, que devem ser explorados antes que essas cinco figuras - os 
quatro Cavaleiros e Pero Dias mártir - possam ser analisadas com mais vagar.

\section{O MARTÍRIO E O JULGAMENTO DAS ALMAS NO CATOLICISMO}

Para entender a natureza das cinco personagens, é preciso entender as diferenças entre elas e outras personagens teatrais. Tanto os Cavaleiros quanto Pero Dias são mártires da fé, isto é, pessoas que morreram pela fé cristã que professavam. Nenhuma dessas presenças em cena pode ser dissociada da problemática do martírio, que pede uma discussão mais aprofundada. O cristianismo é uma religião inteiramente baseada na ideia de martírio. Escreve Renato Cymbalista em sua tese de doutorado:

O martírio de Cristo significou um fator de identidade da religião cristã, e o próprio Novo Testamento deu ao sofrimento de Cristo um sentido exemplar e pedagógico: "por ter ele mesmo sofrido, ao ser posto à prova, pôde vir em auxílio daqueles que estão sendo postos à prova" (Hebreus 2:18). Após o martírio original, o exemplo de Cristo foi seguido pelos seus apóstolos e por muitos outros de seus seguidores cristãos dos primeiros séculos. (CYMBALISTA, 2006, p. 34)

De fato, esta parece ser uma ordem dada por Cristo, que, no Evangelho de São Lucas, diz: "Porque, quem quiser salvar a sua vida, perdêla-á; mas quem sacrificar a sua vida por amor de mim, salvá-la-á" (Lc 9: 24). Durante os primeiros séculos da nossa era, quando os cristãos eram perseguidos pelo Império Romano, os túmulos dos primeiros mártires serviram de local de refúgio e de culto para os sobreviventes, que, baseando no versículo acima citado, presumiam que todo aquele que tivesse sido morto pela fé teria um lugar garantido no Reino dos Céus e, portanto, pediam sua intercessão junto a Deus, para que fossem protegidos. Quando o Império se converte ao cristianismo e à Igreja, essas mortes - traumas coletivos - precisam ser ressignificadas, assumindo um posto essencial da rotina religiosa católica. Os túmulos onde os fiéis tinham encontrado refúgio durante a perseguição tornam-se templos ${ }^{1}$. Os mortos tornam-se um exemplo a ser seguido. O morrer pela fé deixa de ser um risco iminente para a maior parte dos cristãos na Europa durante séculos, retornando ao

\footnotetext{
${ }^{1}$ É a partir dessa forma de homenagem, de acordo com Cymbalista (2006), que nasceu o costume católico de enterrar seus mortos ao redor do tempo religioso: as primeiras igrejas não foram cercadas pelo cemitério; antes, foram construídas dentro dele.
} 
horizonte diante da ânsia por invadir e conquistar Jerusalém, a terra santa, que estava então sob domínio dos turcos.

Depois, na Península Ibérica, o martírio será encorajado novamente dentro da Companhia de Jesus, ordem à qual pertenceu José de Anchieta e cujo objetivo era a propagação da fé católica entre povos não-europeus, o que certamente representaria um risco aos padres missionários. Anchieta ansiava pelo martírio e tinha na mais alta conta seus companheiros de hábito que haviam morrido em nome da fé e da Igreja. A respeito do padredramaturgo, Cymbalista (2006, p. 91) escreve:

Anchieta, antes mesmo de pisar no Brasil, ansiava pelo martírio já na travessia do Atlântico, conforme narra Simão de Vasconcelos: "sem ser compelido, sem ser soldo, sem interesse, propõe de ajudar-vos livremente, até morrer com vossa mesma cruz". O martírio era parte da argumentação dos jesuítas que já encontravam-se no Brasil, clamando por novos companheiros.

É com esse conceito de martírio que nos deparamos ao lermos as duas peças, que também lidarão com a própria questão do destino das almas após a morte. Quase todas as personagens dos textos deixaram a vida terrena para trás e agora enfrentam as consequências das escolhas que fizeram ao longo de sua vida. Esse julgamento, a partir do século XII, passa a tornar-se mais parecido com um julgamento no imaginário europeu: "Deus transformou-se em um grande juiz que determinava a sentença de cada alma. Cristo e os santos advogavam em favor da ida ao Paraíso, o Diabo procurava argumentar pela ida ao Inferno" (CYMBALISTA, 2006, p. 254). No teatro do século XVI, também podemos encontrar vestígios da crença em um julgamento individualizado, que poderia ocorrer no momento da separação entre corpo e alma. Este momento tornara-se crítico para os católicos na Idade Média (CYMBALISTA, 2006, p. 255), cuja religião esteve intimamente ligada ao surgimento do teatro.

\section{O OBJETIVO DO TEATRO RELIGIOSO MEDIEVAL}

As tragédias e as comédias escritas pelos gregos e pelos romanos durante a Antiguidade permaneceram esquecidas durantes vários séculos, de forma que o teatro precisa renascer na Europa medieval. Novas formas teatrais surgem, dissociadas de formas anteriores. E tal qual o teatro clássico, esse novo teatro europeu é embalado no berço da religião 
dominante. Esse teatro predominou entre os séculos X e XV. A partir dos Quinhentos, a redescoberta de formas teatrais clássicas marcou o início de uma nova fase para o teatro europeu.

Na segunda metade do século XVI, um jovem espanhol formado em Coimbra tornou-se membro da Companhia de Jesus e foi enviado ao Brasil como parte da empresa missionária portuguesa na América. Seu nome era José de Anchieta, e ele escreveu, em solo americano, peças religiosas com o objetivo de pregar tanto aos nativos ameríndios quanto aos colonos europeus que, aqui, se encontravam. Sua obra caminha livremente entre as línguas brasílica (o tupi), portuguesa e espanhola, e busca fixar a religião e os valores católicos entre os espectadores.

Tanto Gil Vicente quanto José de Anchieta escreveram suas obras no século XVI. Entretanto, a mentalidade que traduzem é essencialmente medieval, bem como a própria cena para a qual traduzem seus valores morais também o é. José Antonio Saraiva, em seu livro Poesia e drama: Bernardim Ribeiro, Gil Vicente, Cantigas de Amigo, descreve Gil Vicente como "o último representante da Arte da Idade-Média, o último astro que se apaga antes de a claridade da Renascença vir inundar a Terra e o Céu" (SARAIVA, 1990, p. 147). Isso implica que há diversas diferenças entre o que nós, leitores e espectadores do século XXI, pensamos que deveria ser teatro e o que Gil Vicente, Anchieta e seus pares pensavam que deveria ser o teatro.

Essas formas teatrais que prevaleceram entre os séculos $\mathrm{X}$ e XVI dizem respeito a uma cultura e a um pensamento específicos, de forma que há certo "acordo implícito entre autor, actores e público, por uma concepção existencial partilhada unanimemente nos seus valores de crença e fé" (COSTA, 1989, p. 132). As três partes partilham do mesmo sistema de crenças e da mesma visão de mundo e não precisam de traduções. Isto é verdade para o Auto da Barca do Inferno e também para o Diálogo de Pero Dias mártir que, tendo sido escrita em espanhol, dirigia-se certamente a um público majoritariamente europeu.

São peças que cumprem o papel de entreter e de divertir, mas também cumprem o objetivo de pregar aos seus espectadores. Não raro, o público era quem o narrador de $O$ nome da Rosa, de Umberto Eco, chama de "simples": aldeões, pessoas de baixa estirpe social e, portanto, de pouco estudo, como os colonos a quem Anchieta pregava. Gil Vicente, por outro lado, escrevia para a Corte, como veremos a seguir. 
As personagens dos Cavaleiros e de Pero Dias são usadas como exemplo na pregação do padre-dramaturgo e do mestre português. Exemplo do que um bom cristão deve buscar e de como deve viver. E é a esses exemplos que voltaremos nosso olhar e nossa atenção a partir de agora.

\section{OS TEMPLÁRIOS DA CORTE}

José Augusto Bernardes (2003, p. 143-144), professor da Universidade de Coimbra, descreve a chamada Trilogia das Barcas como o resultado de um desdobramento em modelos progressivos e articulados da moralidade de Gil Vicente. De fato, Paul Teyssier assinala que "a peça é designada, por conseguinte, como 'auto de moralidade'" (TEYSSIER, 1985, p. 49). A moralidade é o gênero do teatro religioso medieval em que, de acordo com Hermilo Borba Filho, "se figurava a luta do Bem contra o Mal - ou seja, a luta do poder divino com Satanás, sendo os personagens simbólicos, retratados por meio de alegorias" (BORBA FILHO, 1950, p. 97). Bernardes (2003, p. 143-144) compara a moralidade de Gil Vicente nas Barcas à farsa², no sentido de trazer à cena "um cortejo de enganações (...) só [desveladas] através das acusações do Diabo e do Anjo".

No Auto da Barca do Inferno, peça encenada na corte do rei Dom Manuel de Portugal em 1517 (VICENTE, 2012, p. 62), almas mortais, recémexpiradas, chegam a um porto, onde se deparam com duas barcas. A Barca que leva à Glória - isto é, ao Paraíso - capitaneada por um Anjo, é o transporte preferível, mas uma a uma - num processo quase repetitivo diversas das almas são rejeitadas por ele e encaminhadas à Barca que leva ao Inferno, onde são recebidas pelo Diabo, que ironiza seus pecados e as provoca. Paul Teyssier (1985, p. 50) escreve que

nada pode ser mais característico da arte vicentina do que a composição "processional" desta peça. Não há nela enredo, no sentido usual do termo, mas um desfile de cenas simétricas. Cada um dos pecadores começa por dirigir-se para a barca do anjo mas é repelido e inexoravelmente obrigado a entrar na do diabo - com uma variante

\footnotetext{
2 A encenação da farsa estava frequentemente relacionada ao Carnaval, o que lhe confere também um público menos nobre e mais urbano. Não requer "grandes esforços intelectuais, porque consistem em peças curtas, de duzentos a quatrocentos versos" (MINOIS, 2003, p. 198-199). O espetáculo tende ao violento, ao cômico, ao baixo. Apesar de muitas das peças de Gil Vicente - sobretudo a Trilogia das Barcas - não serem tão violentas, há em sua estrutura algo de farsesco.
} 
significativa para o Judeu que, sendo excluído da sociedade regular e, portanto, até da sociedade dos condenado, será levado a reboque.

Observemos como o Diabo responde à chegada do Onzeneiro ${ }^{3}$ ao porto: “Oh! que maora venhais, / onzeneiro meu parente!" (VICENTE, 2012, v. 182-183, p. 69). Depois, ao saber que a alma morreu justamente quando estava para receber seu pagamento, ele continua: "Ora mui m'espanto / não vos livrar o dinheiro" (VICENTE, 2012, v. 188-189, p. 69). Ao referir-se ao parentesco entre os dois, o Diabo sugere familiaridade, mas isso não impede - de fato, é justamente o oposto: incentiva - o sarcasmo com que reage ao pecado do Onzeneiro.

O enredo se repete, com o engano e as acusações caindo sobre cada uma das personagens, que numa espécie de "o nivelamento ontológico dos mortos, visível nas Danças da Morte, cuja sugestão comparece nas Barcas, especificando, também no plano figurativo, uma matriz de natureza doutrinal" (BERNARDES, 2003, p. 28). A Dança da Morte é um gênero medieval tardio que circulou por diversas regiões da Europa nos séculos XV e XVI, até chegar à Península Ibérica, ganhando algum destaque na Espanha. Nesse gênero, uma representação alegórica da Morte chama pessoas de diferentes estirpe social e idade para dançar ao redor do túmulo. Veem-se exemplos da Dança da Morte na poesia, em gravuras, bem como no teatro.

Tal qual nas Danças da Morte, percebe-se que as personagens do Auto da Barca do Inferno não têm nome. São chamadas, em sua maioria, pelo grupo social que as caracteriza: o Fidalgo, um Moço - servo do Fidalgo, sem falas durante a peça -, o Onzeneiro, o Sapateiro, o Frade, a Moça amante do Frade, que surge com ele na cena, mas que também não fala -, o Judeu, o Corregedor, o Procurador, o Enforcado e os Quatro Cavaleiros. Não possuem, tampouco, traços que as distingam de outras pessoas na mesma condição. Há uma curiosa dualidade em Gil Vicente. De acordo com José Augusto Bernardes (2003, p. 51),

Certamente por se inscrever nesse registro de moralização que o faz, ao mesmo tempo, satirizar a mudança e acreditar nela, Gil Vicente privilegiou os tipos e não os indivíduos propriamente ditos. Há realmente poucos indivíduos no teatro de Gil Vicente.

\footnotetext{
${ }^{3}$ Isto é, agiota. É importante ter em mente que, no século XVI, emprestar dinheiro a juros era considerado pecado grave pela Igreja.
} 
Os tipos sociais são extremamente numerosos no teatro vicentino (TEYSSIER, 1985, p. 124) e são "o objecto das atenções satíricas de Gil Vicente. Todos são atingidos pela sátira. Mesmo o povo miúdo é visado" (TEYSSIER, 1985, p. 155). Na obra do mestre português, a crítica e a sátira servem ao propósito de pregar certa ordem à sociedade, sendo dirigidas "aos homens e não às instituições - e por isso não envolvem qualquer contestação da ordem e da harmonia, nenhuma espécie de revolta contra o Monarca" (TEYSSIER, 1985, p. 160). A crítica feita ao Frade, por exemplo, é feita ao clérigo que não cumpre com seus santos deveres, e não à Igreja:

DIABO:

Fezeste bem, que é fermosa 4 !

E não vos punham grosa ${ }^{5}$

no vosso convento santo?

FRADE:

E eles fazem outro tanto!

DiABO:

Que cousa tão preciosa! (VICENTE, 2012, v. 380-384, p. 76)

As únicas personagens que não são enviadas para a Barca do Inferno são o Parvo Joanes - que, em vez de encontrar seu lugar na Barca da Glória, é deixado na margem do rio, isto é, no Purgatório, à espera da sua vez de seguir viagem (TEYSSIER, 1985, p. 49-50) - e os Quatro Cavaleiros, a quem dirigimos nosso olhar neste momento.

Ao contrário de outras personagens, eles não são satirizados. Não há crítica que seja feita através de sua presença em cena. São, pelo contrário, vistos como exemplo.

O comentário da rubrica diz que cada um traz a Cruz de Cristo, após terem morrido "em poder dos mouros". O texto diz: "Absoltos a culpa e pena ${ }^{6}$ per privilégio que os que assi morrem têm dos mistérios da Paixão d'Aquele por Quem padecem, outorgados por todos os Presidentes Sumo Pontífices $^{7}$ da Madre Santa Igreja" (VICENTE, 2012, p. 93). A condição dos Quatro Cavaleiros é a de abençoados pela Igreja pela morte que sofreram.

\footnotetext{
${ }^{4}$ Referência à beleza da Moça que o Frade traz consigo, sua amante e companheira.

${ }^{5}$ Pôr dificuldades, censurar.

${ }^{6}$ Isto é, "absolvidos de culpa e castigo" (nota de rodapé; VICENTE, 2012, p. 93). Ou seja, os Cavaleiros chegam ao porto livres de seus pecados e, portanto, do castigo que lhes caberia.

7 Papas.
} 
São as únicas almas que não perguntam ao capitão infernal para onde vai sua barca - porque já o sabem muito bem. Assumem uma postura altiva no porto e dizem ao Diabo:

\author{
Vós que nos demandais? \\ Siquer conhecê-nos bem. \\ Morremos das partes d'além, \\ e não queirais saber mais, (v. 847-85, p. 94)
}

Note-se que a recusa se assemelha a uma passagem bíblica em que Jesus Cristo ordena que os homens se esforcem para passar pela porta estreita, pois, a porta será fechada e os pecadores pedirão para entrar. "[O Senhor], porém, vos dirá: Não sei de onde sois; apartai-vos de mim todos vós que sois malfeitores" (Ms 13:27). De acordo com a Bíblia e com a doutrina, Cristo fala do reconhecimento entre Deus e os fiéis, que serão salvos: "As minhas ovelhas ouvem a minha voz, eu as conheço e elas me seguem" (Jo 10:27). Se ambas as passagens sugerem o reconhecimento entre Deus e os salvos, o mesmo pode ser dito do Diabo e daqueles cujo destino é o Inferno. É muito significativo, portanto, que o barqueiro infernal se dirija com familiaridade ao Onzeneiro, mas que seja acusado de ser um estranho para os Cavaleiros: não pode conhecê-los, pois não são seus.

O Anjo também pertence a esse jogo. Se, quando Brísida Vaz se lhe achega à Baca da Glória, responde: "Eu não sei quem te cá traz..." (v. 519, p. 81), mostrando que não sabe sequer por que meios ela chegou até ele, sua reação é completamente diferente quando os Cavaleiros chegam às portas de sua embarcação:

\author{
Ó cavaleiros de Deos, \\ a vós estou esperando, \\ O que morrestes pelejando \\ por Cristo, Senhor dos céos! \\ Sois livres de todo mal, \\ mártires da Madre Igreja, \\ que quem morre em tal peleja \\ merece paz eternal. (v. 855-862, p. 94-95)
}

A postura altiva que os Quatro tinham ao entrar em cena vê-se, era um direito seu, pois até o Anjo os recebe com honras.

Enquanto entram em cena, os Cavaleiros entoam: 


\author{
À barca, à barca segura, \\ barca bem guarnecida, \\ à barca, à barca da vida! \\ Senhores que trabalhais pola vida transitória, \\ memória, por Deos, memória \\ deste temeroso cais! \\ À barca, à barca, mortais, \\ barca bem guarnecida, \\ à barca, à barca da vida! (v. 826-842, p. 93-94)
}

Os Quatro estão seguros de seu lugar na Barca da Glória. Veremos pouco depois, têm absoluta consciência de estarem mortos. Em seguida, emitem um aviso aos pecadores, "que depois da sepultura, / neste rio está a ventura / de prazeres ou dolores!" (v. 837-839, p. 94). Esse aviso dirige-se aos espectadores, os únicos em todo o contexto da encenação que ainda têm a chance de decidir seu futuro: para os Cavaleiros e todas as outras almas, a hora é apenas de receber o veredito.

\title{
O PADRE EM ALTO-MAR
}

A segunda peça em questão, o Diálogo de Pero Dias mártir, foi escrita inteiramente em espanhol, e o também jesuíta Armando Cardoso, crítico da obra de Anchieta, estabelece que deve ter sido encenada em 15 de junho de 1575, na Vila de São Vicente (no atual Estado de São Paulo), no ano de 1592, em Salvador (capital do atual Estado da Bahia) (ANCHIETA, 1977, p. 194). Trata-se de uma homenagem ao jesuíta Pero Dias, português que morrera poucos anos antes na travessia da Europa para a América. Nesse diálogo de 127 versos, escrito em língua espanhola, o mártir conversa com Jesus Cristo, confirmando a salvação de sua alma.

Para o contexto da morte de Pero Dias, o padre Armando Cardoso escreveu que:

Pero Dias fora o narrador do I martírio dos Quarenta, em carta que escreveu da Ilha da Madeira a 17 de agosto de 1570, pouco mais de um ano antes de seu próprio martírio. (...) Embarcou para o Brasil com o B. Inácio, ficando na Madeira, enquanto Azevedo foi às Canárias, onde sofreu o martírio. Pero Dias, constituído Superior dos restantes expedicionários, seguiu viagem no ano seguinte. (CARDOSO in ANCHIETA, 1977, p. 88) 
Em 1571, portanto, uma expedição portuguesa tinha, entre seus objetivos, o de trazer 15 padres jesuítas - incluindo Pero Dias - para a costa do Brasil. "Depois de ter avistado o Brasil, o navio de Pero Dias foi arrastado por correntes marítimas até as Antilhas" (CYMBALISTA, 2006, p. 93). Retomado o curso, a frota foi atacada por navios franceses, liderados pelo capitão protestante João Capdeville. “Doze dos missionários foram trucidados em ódio da fé romana, a 13 e 14 de setembro de 1571. Esse martírio foi narrado por dois companheiros que sobreviveram" (CARDOSO in ANCHIETA, 1977, p. 193).

José de Anchieta teria escrito esse auto em homenagem ao mártir. A Companhia de Jesus tinha muito respeito e devoção pelos mortos pela fé, sobretudo padres e, de forma mais específica, padres jesuítas - eram considerados exemplos. De fato, o Diálogo é inaugurado por um poema em homenagem a Pero Dias, que começa com estes três versos: "Si quieres firmeza y luz, / como el Padre Pero Dias, / sigue al Salvador Mesias" (v. 13, p. $\left.481^{8}\right)$.

Muitas das peças atribuídas ao padre-dramaturgo foram escritas em contexto de recebimento ${ }^{9}$ de algum visitante enviado pela Igreja ou relíquias - isto é, restos mortais ou da vestimenta de santos. No caso do Diálogo, uma imagem teria servido o seu propósito, não como alegoria ao mártir, mas como substituta real dos restos mortais, que haviam sido perdidos em alto-mar (CYMBALISTA, 2006, p. 93).

Na peça, o mártir Pero Dias vê-se diante do próprio Cristo, que lhe pergunta de onde tirou a fé para enfrentar o martírio. $\mathrm{O}$ padre respondelhe que foi Cristo quem a forneceu. O mártir também declara pertencer a Deus. Eis o diálogo que segue:

\footnotetext{
${ }^{8}$ A edição organizada do padre Armando Cardoso coloca o poema de abertura intitulado A Pero Dias junto ao texto, perspectiva com a qual concorda Renato Cymbalista e Paul Teyssier. Maria de Lourdes de Paula Martins, entretanto, separa-os. Dado que essa é uma tendência geral em sua edição - a de separar poema de peça - e a importância do poema para a compreensão do texto, faço aqui essa referência aos versos de abertura do Diálogo.

${ }^{9}$ A saudação lacrimosa era um ritual tradicional dos índios tupi, pelo qual um visitante que chegasse à aldeia ou membro da tribo que retornasse de uma jornada era recebido com lágrimas pelas mulheres, contando-lhe como sua ausência havia sido uma provação para todos e lamentando as fadigas que a viagem lhe devia ter imposto. Esse ritual foi bastante aproveitado pelos jesuítas, que viram uma oportunidade de apresentar à comunidade visitantes ilustres - como padres recém-chegados - ou imagens e relíquias de santos com toda a importância que lhe quisessem conferir. Seria esse o caso de São Vicente, aldeamento indígena administrado pelos jesuítas. No momento de representação, vão-se sete ou nove décadas desde a chegada dos primeiros portugueses e boa parte dos aldeamentos jesuíticos contavam com a presença de europeus, o que significa que há já interação entre brancos e ameríndios que justifique um mesmo ritual de recebimento de relíquias ou padres visitantes.
} 


\section{CRISTO:}

Según dices, ¿es ajena

la fé, que te quise dar, de balde, con mano llena?

PERO:

Confieso que tuya es, y de esa verdad no huyo, mas yo te pregunto, ¿cúyo es lo que me das, después que haces mío lo tuyo? CRISTO:

Tuyo es, pues te lo doy.

Mas dime, ¿tú, cuyo eres?

PERO:

Pues que todo darme quieres, sin duda que tuyo soy, con todo cuánto me diéres. (v. 20-32, p. 460-461)

Percebe-se, aqui, uma postura de absoluta humildade do padre diante de Cristo. A sua vida não era sua, e a fé e a coragem para enfrentar a morte não são suas, mas do próprio Salvador, que o recebe com perguntas. Não se trata de um julgamento, já que, tal qual as almas da Barca do Inferno, os feitos em vida é que contam para o veredito. Antes, é um convite à reflexão sobre a vida cristã e a proteção conferida por Cristo, que diz:

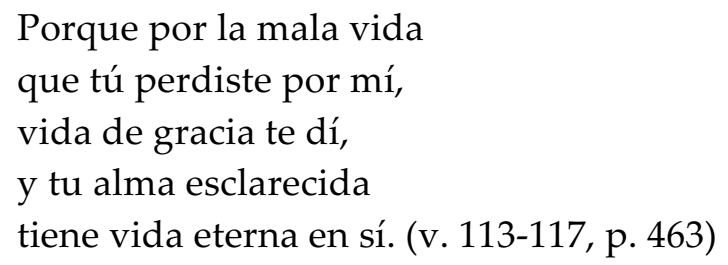

Escrevendo-se a peça em língua castelhana, a representação provavelmente aponta para um público majoritariamente branco - isto é, majoritariamente católico. A mensagem que se prega, portanto, volta-se a europeus presentes na Vila de São Vicente ou em Salvador no momento da encenação. $\mathrm{O}$ exemplo dado é para os padres, sob o constante risco de morrer por doença, acidente, ataque de feras ou pela mão de inimigos, quer ameríndios, quer europeus.

Para o branco, a mensagem é a de respeito por almas que certamente seriam recebidas no Paraíso, sem passagem pelo Purgatório. 
Era essencial o respeito pelos clérigos, que precisavam da proteção e mereciam o respeito e a obediência dos colonos.

\section{ALTIVEZ E HUMILDADE: DUAS POSTURAS OPOSTAS DIANTE DO MARTíRIO}

Ao ler ambas as peças, percebemos uma nítida distinção entre os textos no que diz respeito à morte dos mártires e à própria vida. Lembremo-nos do que disse Dalila Pereira Costa, citada anteriormente neste texto, quando diz que "a ideia da morte é mais reveladora da essência do pensamento do homem do que a ideia da vida" (COSTA, 1989 p. 57). Cada uma das peças analisadas apresenta a quem as assiste ou lê uma perspectiva do que ocorre após a morte. Em ambas, pode-se ver homens que, por morrerem pela fé, são enviados diretamente ao Paraíso. As formas como são direcionados ao seu local de descanso eterno, entretanto, são distintas.

No Auto da Barca do Inferno, de Gil Vicente, Quatro Cavaleiros mortos na África, enquanto combatiam os mouros, encontram no porto o Diabo, que tenta chamar sua atenção, e o Anjo, que os parece ter em alta conta por seus feitos. A postura dos Cavaleiros é altiva diante do primeiro barqueiro e silenciosa diante do último. São recebidos pelo Anjo, que diz:

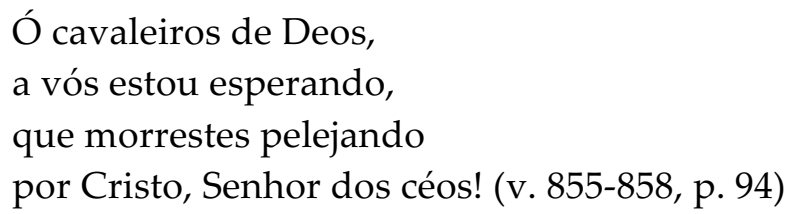

Mas não lhe dizem nada. Permanecem silenciosos ao tomarem seus lugares na Barca da Glória, que zarpa em seguida.

Por outro lado, Pero Dias, no Diálogo que José de Anchieta lhe dedicou, encontra-se com o próprio Cristo, a quem atribui todo o crédito pelo seu martírio e sua ulterior salvação. Sua postura é de total humildade diante do Salvador.

As diferentes posturas podem estar associadas ao perfil das almas. Se os Cavaleiros são guerreiros de nobre estirpe enviados à África, o prestígio em vida serviu-lhes de preparação para o prestígio que receberiam após a morte. Pero Dias, ao contrário, era um membro do clero, e a soberba e sede por fama não estavam entre os anseios incentivados pela Igreja. Não cairia bem a um padre, em uma peça escrita por outro padre, a 
distinção que, em uma peça escrita para a corte portuguesa, parece tão apropriada.

Para além disso, são as almas recebidas por personagens de naturezas muito diversas. O Anjo está a serviço de Deus e dos Santos, sendo encarregado de levar as almas ao Paraíso. Não se trata, certamente, da mais prestigiosa das tarefas, a julgar pela interação com mortos condenados e pela proximidade do próprio Diabo. Pero Dias é recebido pelo próprio Cristo, de forma que não haveria, na hierarquia católica, ninguém em posição mais elevada.

Finalmente, voltamo-nos para a figura dos autores. Se Gil Vicente encenava suas peças para a corte portuguesa, José de Anchieta escrevia para a colônia americana. O primeiro, um leigo, e o segundo, um padre jesuíta, não tinham certamente o mesmo prestígio, apontando para perspectivas diferentes diante da vida, da morte e do próprio martírio.

Apesar das diferenças entre as duas peças, o destino dos mártires é sempre o mesmo. Declara-o o Anjo da Barca em uma fala que nos deverá apontar novamente ao versículo de São Lucas referido no início deste artigo:

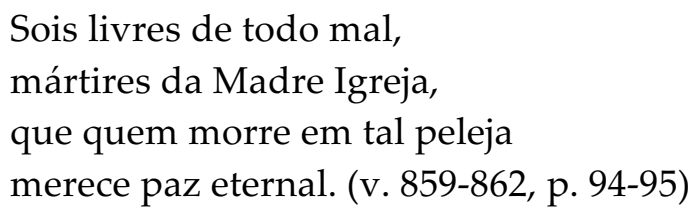

Cristo também, neste trecho do Diálogo, reafirma a reconquista de uma vida - eterna - prometida pelo mesmo versículo:

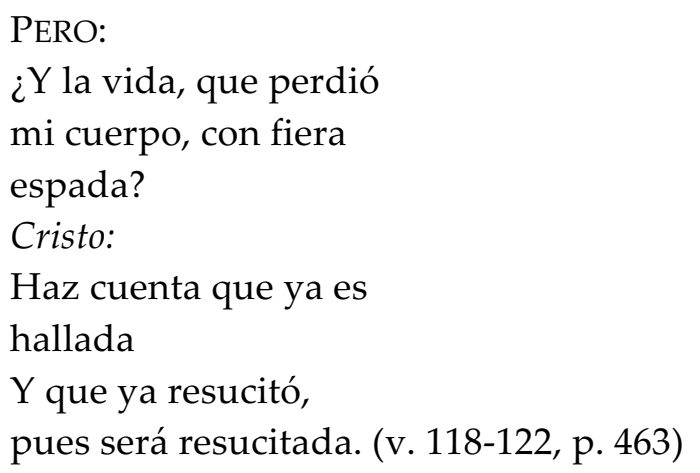

Àqueles que morrem pela fé é garantida a salvação, e suas almas são recebidas com honras pelos Santos. Gil Vicente e José de Anchieta representam-nos com respeito, buscando inspirá-lo também em seus 
espectadores. O exemplo dos mártires serve de incentivo para os cristãos que se veem diante do mesmo risco de morte - ou da possibilidade de apoiar e proteger a Igreja e seus representantes.

Apesar do caráter cômico de boa parte das peças de Anchieta, o Diálogo de Pero Dias mártir traz a mesma solenidade associada à chegada dos Quatro Cavaleiros à Barca da Glória no Auto da Barca do Inferno. Os mártires não debocham, pois estão mais próximos dos santos do que de outros seres humanos. Tanto o Anjo quanto Cristo os recebem de braços abertos. A Salvação lhes é garantida, e as cinco almas a recebem com convicção.

\section{REFERÊNCIAS}

ANCHIETA, José de. Poemas - Manuscritos do século XVI, em português, castelhano, latim e tupi. Transcrição, tradução e notas de M. de L. de Paula Martins. São Paulo: Museu Paulista, 1954.

ANCHIETA, José de. Teatro de Anchieta; introdução, notas e tradução de Armando Cardoso. São Paulo: Edições Loyola, 1977.

BERNARDES, José Augusto Cardoso. Revisões de Gil Vicente. Coimbra: Angelus Novus, 2003.

BORBA FILHO, Hermilo. História do teatro. Rio de Janeiro: Livraria-Editôra da Casa do Estudante do Brasil, 1950.

COSTA, Dalila Pereira. Gil Vicente e sua época. Lisboa: Guimarães Editores, 1989.

CYMBALISTA, Renato. Sangue, ossos e terras: Os mortos e a ocupação do território luso-brasileiro - séculos XVI e XVII. 2006. 428p. Tese (Doutorado) Programa de Pós-Graduação da Faculdade de Arquitetura e Urbanismo Doutorado em Concentração, História e Fundamentos da Arquitetura e Urbanismo. Universidade de São Paulo.

ECO, Umberto. O nome da rosa. Rio de Janeiro; São Paulo: Editora Record, 2019.

MINOIS, Georges. História do riso e do escárnio. São Paulo: Editora UNESP, 2003. 
SARAIVA, José Antonio. Poesia e drama: Bernardim Ribeiro, Gil Vicente, Cantigas de Amigo. Lisboa: Gradiva, 1990.

TEYSSIER, Paul. Gil Vicente: o autor e a obra. Lisboa: Instituto de Cultura e Língua Portuguesa, 1985.

VICENTE, Gil. Autos; organização, apresentação e ensaios de Cleonice Berardinelli. Rio de Janeiro: Casa da Palavra, 2012.

Os excertos bíblicos foram extraídos da Bíblia Ave Maria. Versão online disponível no site dos Missionários Claretianos Brasil em: http://www.claret.org.br/biblia. Acesso em 30 de abril de 2020.

Recebido em 22 de outubro de 2020

Aprovado em 20 de novembro de 2020

Licença: (c) (7) \$)

Marina Gialluca Domene

Mestre em Literatura Portuguesa e Graduada em Letras (Português-Inglês) pela Universidade de São Paulo.

Contato: marinagialluca@gmail.com

(iD) https://orcid.org/0000-0002-7471-5928 